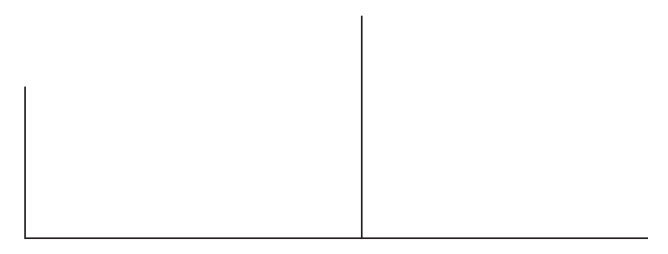

\title{
Os delírios passionais: erotomania, reivindicação, ciúmes ${ }^{1}$
}

\author{
Gaëtan Gatian De Clérambault
}

\section{Apresentação do doente \\ 1921}

Apresentamos aqui um resumo da discussão que precede a apresentação do Dr. Clérambault. A aula integral será publicada nas Annales Médico-Psychologiques.

1. O delírio erotomaníaco não é um delírio de interpretação, mas uma síndrome passional patológica.

É oportuno agrupar essa síndrome junto com os delírios de reivindicação e delírios de ciúmes na categoria "delírios passionais patológicos”.

Os delírios de interpretação têm por base o caráter paranóico, isto é, um sentimento de desconfiança. Desenvolvem-se em todas as direções e implicam na personalidade global do sujeito; este não está excitado; os conceitos são múltiplos, variáveis e progressivos; a extensão ocorre por irradiação circular; não é possível determinar o momento de início etc.

As síndromes passionais caracterizam-se por sua patologia, seus componentes tanto comuns quanto específicos,

1. Tradução de Alain François e revisão técnica Prof. Dr. Mário Eduardo Costa Pereira (Laboratório de Psicopatologia Fundamental-UNICAMP). 


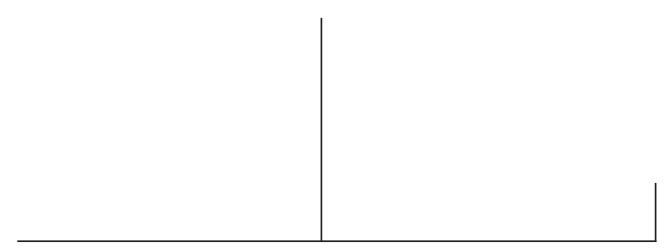

seus mecanismos ideativos, sua expansão polarizada, sua hiperestenia (que chega, às vezes, a um comportamento hipomaníaco), a implicação inicial da vontade, a noção de finalidade, o conceito diretor único, a veemência, as concepções imediatas e completas, um comportamento de reivindicação banal etc.

As síndromes passionais patológicas apresentam-se quer autônomas e puras, quer associadas a outros delírios (intelectuais ou alucinatórios). Elas são, portanto, quer prodrômicas, quer suplementares. Via de regra, quanto maior sua pureza, maior sua intensidade.

O delírio erotomaníaco desenvolve-se segundo três estágios: esperança, desdém e ressentimento.

As concepções do delírio erotomaníaco dividem-se em:

1) postulado inicial;

2) deduções oriundas desse postulado (dados relativos ao objeto);

3) temas imaginativos e de interpretação diversos (dados a respeito dos incidentes da perseguição amorosa).

Entre essas concepções, algumas são específicas e têm muita importância para a orientação do interrogatório, primeiro como objetivos, mais tarde como elementos de convicção para o médico. Não devemos nos ater aos fatos (que o doente sempre pode negar), mas, outrossim, aos pontos de vista do doente que transparecem nas fórmulas específicas.

Para examinar esses pacientes, não basta entrevistá-los: é também preciso “acioná-los”. É de suma importância conseguir ativar o elemento esperança sempre presente na síndrome erotomaníaca. Sem essa manobra, muitos erotômanos que deveriam ser classificados como perseguidos amorosos continuariam classificados entre os perseguidores-perseguidos.

2. O sentimento que gera o postulado é um misto de orgulho, desejo e esperança. As evoluções e as reações dependem, em sua maior parte, do caráter individual, do grau de moralidade e da educação.

Consideramos como específicas as seguintes concepções:

a) Postulado fundamental: $O$ objeto é quem começou a amar e ama mais ou, então, é o único a amar.

(N.B.: objeto geralmente elevado, concepção clássica).

b) Temas derivados e considerados evidentes:

$O$ objeto não pode ser feliz sem o(a) pretendido(a).

$O$ objeto não pode estar completo sem o(a) pretendido(a).

O objeto está livre. Seu casamento não tem valor.

c) Temas derivados, que podem ser comprovados:

Vigilância contínua por parte do objeto.

Proteção contínua por parte do objeto. 
R $\quad E \quad V \quad$ I $S$ S $T$ T

LATINOAMERICANA

DE PSICOPATOLOGIA

F UNDAMENTA L

Intrigas de aproximação por parte do objeto.

Conversas indiretas com o objeto.

O objeto dispõe de recursos enormes.

O romance em curso inspira uma simpatia quase universal.

Comportamento paradoxal e contraditório do objeto.

Encontrar todas essas fórmulas juntas seria um fato excepcional. A última (comportamento paradoxal), sempre presente, tem uma importância capital, por permitir a acomodação com os fatos: supõe-se, por exemplo, que o objeto hesita por orgulho, timidez, dúvidas, ciúmes, ou então por abulia inata; ou que um amigo misterioso o domina de maneira inacreditável; ou, ainda, que o objeto quer pôr o sujeito à prova etc.

Todas essas concepções dizem respeito ao comportamento do objeto. Mais tarde, desenvolvem-se idéias de perseguição relativas aos incidentes da perseguição amorosa. Estas não são difusas; nesse momento estão rigorosamente agrupadas em torno da idéia de perseguição. As perseguições emanam do próprio objeto ou têm por objetivo afastar-se dele.

Por uma reversão psicológica de ordem geral, nos estados de desdém e de ressentimento, o sujeito, impaciente e humilhado, acredita odiar. As lamentações, inicialmente hipócritas, tornam-se sinceras. O sujeito passa a reivindicar. Argumenta a respeito de prejuízos passados, claramente fictícios, e de prejuízos recentes que, embora reais, podem apenas ser imputados a ele mesmo. Resta a esperança inconsciente.

Se os temas de perseguição secundários se desenvolverem e o delírio tender a se espalhar, poderemos presumir que o delírio erotomaníaco não é puro, mas, antes, associado. A expansão irradiante que leva a um conjunto de perseguições banais confirma que a erotomania pode ser prodrômica ou secundária.

Nos casos puros, não há concepções megalomaníacas globais e absurdas, nem retrospectivas. Nunca há alucinações.

As concepções específicas enunciadas acima diferenciam o delírio erotomaníaco da assim chamada paixão normal.

Observação - Vinheta de internação

Léontine D., 28 anos, operária. Erotômana. Estágio do desdém. Interpretações secundárias ao mesmo tempo hostis e favoráveis. Um capitão, para quem trabalhou, quer casar-se com ela e mesmo assim a persegue. Inumeráveis colaborações. Manifestações. Intrigas. Cartas ao mesmo tempo acusatórias e afetuosas. Diligências de aproximação e declarações implícitas. Expectativas. Injúrias e ameaças contra a mulher do capitão. Recusa-se a acreditar que esteja casado. Exagero de personalidade. Apresenta um grau de jovialidade e 
expansividade insólito nessa forma de delírio. Possibilidade de delírio polimorfo em início de evolução.

Dr. Clérambault (Enfermaria especial), 1 de fevereiro de 1921.

Informações

Na Enfermaria especial, a paciente tanto admite sem maiores dificuldades que seu perseguidor começou com desejos matrimoniais, como confirma o comportamento paradoxal deste. Em compensação, nega terminantemente sentir ou ter sentido qualquer inclinação para com ele. Contudo, 1) sustenta que ele não é casado e, 2) admite a possibilidade de perdão. Acaba confessando que casar-se-ia com ele, caso aceitasse mudar seu comportamento (fórmula específica).

Confrontada com seu perseguidor, censura-o por permanecer em silêncio. Quando lhe perguntam: “Gostaria de se casar com ele?”, a doente nega embora se mostre radiante; em seguida, alega apenas precisar conhecer melhor seu caráter antes de concordar e, além do mais, argumenta não caber às mulheres declararse antes dos homens.

Gostaria de ser sua amante? De forma alguma. No entanto, objetamos, não se pode conhecer um homem sem se ter vivido com ele. Numa série de respostas graduais (que seria longo demais detalhar aqui), acaba aceitando a idéia de um "casamento de experiência”, a ser legalizado mais tarde. Já no dia seguinte sairão em busca de uma casa e de mobília. Sai indignada com o silêncio do oficial, mas, solicitada de novo, escreve uma carta em que repete que no dia seguinte ela e o capitão buscarão uma casa para abrigá-los durante o período de experiência.

As idéias de perseguição estão polarizadas. Até então, se perdeu seus empregos, se alguns músicos vão tocar em restaurantes, se sua família não concorda com ela, tudo se deve à influência exclusiva do oficial. O delírio de perseguição parece, entretanto, ter uma certa tendência em expandir-se, o que o diferenciaria do tipo erotomaníaco puro.

Em Sainte-Anne, no dia da sessão da Société Clinique, encontramo-la um tanto azeda, muito abalada pelo internamento, pelo qual culpa o oficial e aborrecida pelos constantes interrogatórios. Insulta o oficial.

\section{Apresentação}

Durante a sessão da Société Clinique, embora fale pouco, mostra-se sorridente. Sustenta que o oficial a amava ao passo que pla nem pensava nele. 


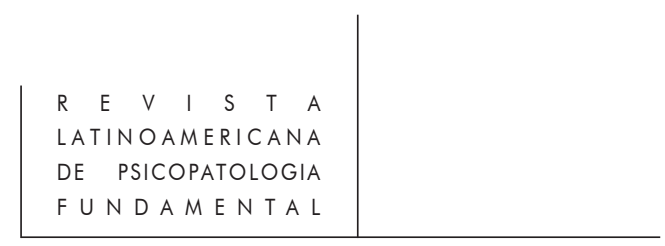

Ficou sabendo do amor dele por ela pelos comentários de suas colegas. Longe de amá-lo, tinha, antes, uma aversão por esse oficial que tinha um ar frio e altivo; os olhos azuis, comentados por todas as mulheres, produziam nela um efeito desagradável (sic). Garante nunca ter sequer lhe dirigido uma palavra ou um olhar que pudessem revelar seu amor. Quando lhe perguntam se casaria com ele, a princípio nada tem contra, embora ensaie algumas objeções que deixa em suspenso. O oficial devia ter falado com ela; como enamorado, teve um comportamento muito estranho etc. Quando propomos intervir, a doente parece recusar nossa oferta; basta, no entanto, reiterarmos a proposta para que se despeça com um "obrigada” alegre.

Durante o diálogo, confirmou de várias maneiras o comportamento paradoxal do capitão, cujo casamento negou; está, no entanto, disposta a perdoá-lo.

\section{Comentários}

O psiquiatra que apresenta o caso observa que o oficial, desde o primeiro dia, produzira uma impressão profunda na doente cuja paixão nascera antes de qualquer interpretação. A doente pensou que comentassem a respeito dela e do oficial apenas porque pensava nele de modo intenso. Além do mais, ela não parece ter interpretado a seu favor, pelo menos de início, qualquer olhar ou gesto do oficial. Sua paixão fora mesmo espontânea; o trabalho de interpretação veio a seguir. É natural que suas interpretações tenham se desenvolvido no sentido de seu desejo: o contrário seria inadmissível.

A delirante buscou aproximar-se do objeto com falsos pretextos (mudanças de trabalho, lembranças de incidentes passados ou francamente duvidosos etc.). Nega que o oficial seja casado e censura seu comportamento contraditório e paradoxal. Interrogada de modo adequado, declara-se disposta a perdoá-lo. Esses dados são constantes nesse tipo de casos. A paciente ainda está no estágio de desdém; conserva, entretanto, sua esperança consciente. Embora reticente, parece ligeiramente hipomaníaca; este também é um traço comum.

O psiquiatra que apresenta o caso indaga se este continuará sendo, por muito tempo, um caso de erotomania essencial. De fato, a paciente, apesar de sua reticência, é expansiva até o excesso; suas idéias de perseguição tendem a tornarse difusas, enfim, trata-se claramente de uma retardada mental. Todas essas razões parecem indicar o início de um delírio polimorfo de expansão gradual; nessa doente, a erotomania não seria, portanto, senão prodrômica. 
Em todas as formas mentais pode-se observar um substrato afetivo: delírios maníacos ou melancólicos, obsessões ou fobias, anomalias sexuais e delírios de perseguição. Podemos encontrá-lo até na origem dos espasmos e dos tiques. Não basta, portanto, mencionar o elemento afetivo: é preciso ainda defini-lo e avaliar sua intensidade.

O paranóico delira segundo seu caráter. Via de regra, este é o produto das emoções cotidianas mínimas que alcançaram a condição de habituais, cuja qualidade é preestabelecida para a vida toda e cuja medida está mais ou menos prefixada diariamente. No passional, em compensação, produz-se um nó ideoafetivo inicial cujo componente afetivo consiste numa emoção veemente, profunda, destinada a perpetuar-se sem fim e que monopoliza todas as forças da mente, desde o primeiro dia.

O sentimento de desconfiança do paranóico é muito antigo, o que impossibilita a determinação do início do delírio no passado. Em compensação, a paixão, no erotômano e no reivindicador, tem um ponto de início preciso. A desconfiança do paranóico regula as relações de seu Eu total para com o conjunto de seu meio ao qual conforma a concepção subjetiva do Eu. A paixão do erotômano ou de reivindicador não modifica a concepção subjetiva do Eu nem suas relações com o meio a não ser na esfera da e durante a paixão.

Esses diferentes pontos de partida têm repercussões no tom psíquico geral e na expansão do delírio.

O passional (erotômano, reivindicador ou ciumento) tem, desde o início do delírio, uma finalidade precisa; seu delírio implica imediatamente sua vontade. Trata-se, portanto, de um traço diferencial, uma vez que o delirante interpretador vive num estado de expectativa e o delirante passional num estado de esforço. O delirante interpretador vagueia pelo mistério, inquieto, pasmo e passivo, cogitando a respeito de tudo que observa, buscando explicações que descobre paulatinamente. O delirante passional, por sua vez, avança rumo a um objetivo, com uma exigência consciente completa desde o início e delira apenas na esfera de seu desejo: tanto suas elucubrações como sua vontade estão polarizadas de maneira proporcional a esta última.

O modo de expansão do delírio será, portanto, particular. Uma vez que todo o trabalho - imaginativo e de interpretação - se restringe, por assim dizer, ao espaço que se estende entre o objeto e o sujeito, o desenvolvimento das concepções não se dará em círculos, mas por setores. Mesmo se seus enfoques se ampliam, permanecerão no mesmíssimo setor cujo ângulo não varia. Pelo contrário, as concepções do paciente interpretador irradiam-se constantemente em todas as direções, recorrem a todos os acontecimentos e a todos os objetos 
(embora em alguns doentes as concepções mudem gradativamente de tema); sua expansão é irradiante, o sujeito vive no centro de uma rede circular e infinita.

De um tal trabalho, o sujeito conclui que sua personalidade está ameaçada ou, então, exaltada; ele se vê quer no centro de uma conspiração geral, quer como dono e senhor do mundo. Por vias diferentes, Leroy, por um lado, Sérieux e Capgras, por outro, sublinharam a ausência de megalomania absurda e de transformação do meio nos pacientes reivindicadores.

Muitas vezes o paciente interpretador tem opiniões retrospectivas, indo buscar explicações no passado, pois ao contrário do passional que está com pressa, ele tem tempo. O passional, movido essencialmente pela vontade, tende para o futuro.

As primeiras e mais importantes convicções do erotômano têm sua origem nesse postulado. Nada de semelhante pode ser observado no paciente interpretador. Não se pode descobrir nele qualquer idéia-mãe de onde se desprenderiam cadeias de idéias; suas idéias provêm, por assim dizer, de todos os pontos de sua mente; embora não estejam subordinadas umas às outras, estão coordenadas entre si, e, mais importante, não estão subordinadas a uma única idéia. Se suprimirmos, no delírio de um paciente interpretador, a idéia que parece mais importante, ou até várias delas, teremos furado uma rede, mas não as cadeias; a imensa rede perdurará e outros elos se reconstituirão sozinhos. Em compensação, se suprimirmos no delirante passional, a única idéia que chamei de postulado, veremos o delírio inteiro ruir. Como a lágrima batávica, basta quebrar-lhe a ponta para que desvaneça.

Uma vez desaparecido seu delírio, só restará ao sujeito produzir outro quando se encontrar maduro para um novo acesso passional. Uma experiência dessas é absolutamente impossível nos casos de erotomania; um pouco menos impossível nos casos de pacientes reivindicadores; pode vir a realizar-se nos delírios ciumentos, caso o suposto rival parta ou morra; nessas circunstâncias o delírio pode suspender-se durante um tempo bastante prolongado antes de renascer, uma vez que sua fonte reside não apenas na paixão, mas também, em maior grau, no caráter.

Nenhuma das convicções do paciente interpretador pode ser considerada equivalente ao postulado. Não há idéia diretora no postulado cuja característica é de ser primário, fundamental e gerador. As conviç̧ões explicativas do paciente interpretador são secundárias a inumeráveis interpretações. Não há célula-mãe neste tipo de delírio. Seria incorreto dizer que existe uma idéia prevalente nos pacientes interpretadores, a menos que se retire desse termo seu sentido de idéia original para lhe conferir apenas um sentido sintomático muito extenso, fazendoo corresponder à palavra "obsessão" da linguagem leiga, isto é, a de uma idéia recorrente, assediadora. Nesse caso, entretanto, não encontraríamos uma, mas 
várias idéias prevalentes nos pacientes interpretadores. A psiquiatria alemã estende o termo "prevalência" aos delírios de interpretação e àqueles que chamamos de passionais, às obsessões e fobias, bem como às idéias melancólicas; isso só se sustenta de um ponto de vista semiológico, isto é, se abstrairmos a mecânica do delírio. O termo "idéia prevalente", em seu sentido estrito, convém apenas aos passionais, embora não completamente, uma vez que parece atribuir a predominância, nos distúrbios ideo-afetivo, ao elemento ideativo (o que, temos de convir, não é a intenção dos autores). Por outro lado, esse termo não salienta o valor de embrião lógico que atribuímos ao postulado, razões pelas quais o temos evitado.

Nesse nó ideo-afetivo que constitui o postulado, o primeiro elemento, em termos cronológicos, é evidentemente a paixão. Em nosso caso, a paciente afirma que nada, nos olhares, nas atitudes nem na fala do objeto, lhe sugeriu que pudesse ser amada. Segundo ela, ficou sabendo pelos comentários de suas companheiras. Entretanto, mesmo admitindo que tais comentários existiram, não bastaram para gerar o estado passional. Por outro lado, nossa paciente deixa transparecer o quanto ficou obcecada, desde o primeiro dia, pelo olhar fascinante do objeto; enfim, a eventual alteração da verdade por parte de suas companheiras se deve à atração que estas perceberam nela.

O mecanismo passional da erotomania explica seu surgimento paulatino de modo hipomaníaco. Como o paciente reivindicador, o erotômano é um excitável excitado no qual Leroy, Capgras e Sérieux sublinharam esse traço. Pode-se dizer, além do mais, por causa da noção de objetivo dominante desde o início, que o erotômano, desde antes da fase de desdém, é um reivindicador, embora benevolente.

Sérieux e Capgras já distinguiram os pacientes reivindicadores dos interpretadores. Concordamos com todos seus critérios diferenciais e acrescentamos a noção de que ambos dependem de um único dado: a patogênese passional. De fato, são traços passionais: o entusiasmo inicial; o objetivo único e consciente desde o início; o esquecimento de qualquer interesse alheio à paixão (donde deriva a restrição, segundo acreditamos típica, das idéias de perseguição e de grandeza, aos interesses exclusivos da paixão), assim como a ausência habitual, assinalada por esses autores, de exageros absurdos nas concepções terminais.

Embora os delírios passionais sejam mesmo muito interpretadores, a interpretação é uma constante dos estados emocionais, mas é secundária, nos dois sentidos da palavra, nos delírios passionais; caso adquira alguma importância, seu desenvolvimento não ocorre em linha reta, mas segundo constelações limitadas. 


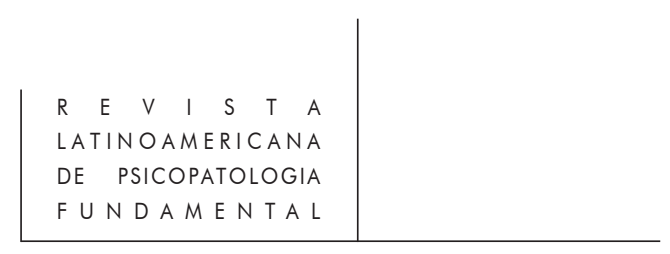

A interpretação somente se torna invasora nos casos mistos. A associação das diversas formas intelectuais (interpretações, reivindicações, erotomania e ciúmes) é freqüente, embora os estudos de casos puros nos inclinem a não atribuir a cada fator senão o que dele resulta.

As síndromes passionais associam-se igualmente aos delírios alucinatórios com ou sem demência. Mais uma vez, tratam-se de casos mistos, ideais para nos permitir julgar melhor os precedentes.

Sendo essas síndromes psicológicas, não se deve estranhar vê-las atuar de modo incidental nos mais variados terrenos. Mal se manifestam e já marcam a implicação de um elemento de volição até então ausente, característico da paixão.

Todos os critérios diferenciais entre delírio de interpretação e delírio de reivindicação, tão bem descritos no livro de Sérieux e Capgras, continuam valendo para distinguir o delírio de interpretação do delírio erotomaníaco. Se nossa argumentação não fosse aceita, a deles também estaria correndo perigo.

Continuamos considerando específicas as fórmulas que demos como tais, uma vez que estas permitem distinguir a paixão dita normal do delírio passional dos perseguidores-perseguidos não enamorados.

De fato, nenhum apaixonado normal e infeliz esconde em si nosso postulado, ou seja, acredita ser mais amado do que ama, nem pretende conhecer os pensamentos verdadeiros do objeto melhor do que este. Nunca considerará o comportamento do objeto para consigo como totalmente paradoxal (que o objeto, por exemplo, lhe sorri ao mesmo tempo em que o manda prender), nem que uma multidão de pessoas se interessa pelo seu romance. Também não negará que o objeto esteja casado. Todos os seus esforços, se existirem, serão voltados para a idéia de que poderá e pode conseguir ser amado, dado incompatível como o postulado.

Essas fórmulas também distinguem os perseguidores-perseguidos não amorosos dos erotômanos convertidos em perseguidores. Um perseguidorperseguido nunca exprime a idéia de um comportamento totalmente paradoxal por parte de seu inimigo, pelo simples fato de carecer de motivos para assim pensar; um comportamento duplo pressuporia um sentimento duplo. Ora, qual seria, para o perseguidor-perseguido, esse sentimento que o seu inimigo banal está sentindo? Ele pode eventualmente alegar, ao se referir a algum ato de seu inimigo, tratar-se de uma encenação; tem perseguidores, por exemplo, para os quais a guerra não passará de uma encenação que lhes era destinada. Será essa apreciação válida para todos os comportamentos do inimigo imaginário? Aplicarse-á a ele apenas? Trata-se de um doente sem megalomania e sem déficit intelectual? Ou, então, de um paciente em posição de perseguidor-perseguido em idade de erotomania que persegue um objeto do outro sexo? Este é o ponto crucial. Uma fórmula clínica não vale senão por suas condições de apresentação. 
É o que acontece com as fórmulas típicas dos perseguidos comuns e dos melancólicos aos quais nos referimos.

Em resumo, é de conhecimento geral que não se pode estabelecer um diagnóstico baseado num único sintoma. Todo sintoma contém margem para erros. Nossas fórmulas são específicas apenas à medida que um sintoma clínico pode sê-lo; e se muitos casos diferentes apresentarem fórmulas idênticas, será uma curiosidade interessante que não impedirá, no entanto, que as fórmulas sejam muito úteis para estabelecer o diagnóstico e chegar a uma conviç̧ão caso formem um conjunto concordante.

Mesmo se nos equivocarmos, o seguinte continuaria valendo: o quadro completo da erotomania não aparece em lugar nenhum. Não encontramos nos tratados mais do que descrições sem método as quais não evidenciam constantes, nem fornecem qualquer tipo de plano ou de critério com vista ao interrogatório. Essas constantes, esses critérios e o modelo desse plano ainda estão esperando por uma formulação. Tratamos de estabelecer uma, uma vez que os casos de erotomania são abundantes em nossos ambulatórios. 